\title{
A Novel IoT Based Approach to Notify Motion Detection in User's Absence through Handheld Devices
}

\author{
${ }^{1} \mathrm{~K}$ Murali Krishna, ${ }^{2}$ Dr H Jayashree \\ ${ }^{1}$ Assistant Professor, Maturi Venkata Subba Rao Engineering College, Hyderabad, Telangana \\ ${ }^{2}$ Professor, Maturi Venkata Subba Rao Engineering College, Hyderabad, Telangana
}

Received: 13 March 2020; Accepted: 13 May 2020; Published: 08 June 2020

\begin{abstract}
Security Camera Notifier helps detect any motion (i.e., suspicious activity) happening in the personal room in the user's absence. Nowadays, privacy \& security are major concerns. User can install a security camera in the room which helps them to keep their belongings \& any other important things safe under surveillance. Unlike other CCTV activities, this process doesn't require $24 \mathrm{hrs}$ surveillance. It doesn't require a long list of equipment like big cameras or a big screen (say TV) to watch activities or even a heavy budget. It is simple and easy to install. A stranger wouldn't be able to guess that there's a secret security camera installed in the room. This protocol works when a hidden camera placed in the room detects any motion in the user's time off. A notification is sent to users mobile; the moment the camera detects any kind of motion (say someone entering the room). Here, the user would be provided with '@snap' function, if he/she sends '@snap' then the camera will capture a live picture of that moment and send it to the Smartphone. So, by this process security of the room is assured in user absence.
\end{abstract}

Index Terms: Snap, security, hidden camera

(C) 2020 Published by MECS Publisher. Selection and/or peer review under responsibility of the Research Association of Modern Education and Computer Science

\section{Introduction}

Safety and security is a major concern now a days, a surveillance camera costs us very high. Taking present scenario into consideration, surveillance camera requires heavy setup. It need a person to be present there for

\footnotetext{
* Corresponding author

E-mail address: muralikrishna_cse@mvsrec.edu.in, jayasree_cse@mvsrec.edu.in
} 
$24 \times 7$ to check out the activity(mischievous) happening. Since it requires heavy work it also costs us very high and also difficult to maintain. The main objective is to provide security and safety that costs us low compared to video surveillance system. In this paper, we are presenting a solution which is smaller in size and its cost less.

Security Camera Notifier is a camera application which detects motion and notifies to mobile. It notifies with captured images and videos when motion is detected. The notification accompanies content, still picture or video that the client can see it directly on their iOS or Android gadgets. It can be easily and secretly installed in a small room. Since it's a small hidden camera, an unknown person won't easily notice the camera installed in the room. The application is truly basic. It uses the product and administrations, for example, Pi-Camera and Push Bullet Application.

\section{Literature Survey}

Holloway Prison in 1913 as the first time "modern photographic surveillance" was the first one to be use. The guards took "photographs covertly, from far away, and without the inmates' knowledge or consent" ${ }^{\text {"1]. The }}$ reason behind this was "a specific group of inmates refused to have their pictures captured, and further pose in different angles to make it different for identification. Each time they saw someone attempting to take photographs of them, these surveillance camera players would accomplish something — cover up their faces, make "funny" faces, decline to keep still - to ruin the final product, to make it futile in recognizing them. These fanatics were called suffragettes."

In 1942 Walter Bruch installed a closed-circuit television framework for Siemens at the Test Stand VII rocket launch site in Peenemunde, Germany to securely screen any reason of breakdown or issues from the rocket launches.

A videocassette recorder, $\mathrm{VCR}^{[5]}$, or video recorder is an electromechanical device that records simple sound and simple video from communicating TV or another source on a removable, alluring tape videocassette, and can playback the recording. Utilization of a VCR to record a TV program to playback at a progressively helpful time was observed.

The Video Home System ${ }^{[2]}$ (VHS)is a standard for shopper level simple video recording on tapes. Developed by Victor Company of Japan(JVC) ${ }^{[1]}$ in the mid-1970s, it was discharged in Japan in late 1976 and the United States in mid-1977s. JVC engineers Yuma Shiraishi and Shizuo Takano set up together a group to build up a purchaser based $\mathrm{VTR}^{[6]}$.

The second attack on the World Trade Center, and its subsequent destruction, pushes the public towards more personal-safety oriented surveillance. As a result, facial recognition programs and other digital advances became a higher priority. Internet based surveillance cameras become increasingly common.

Using the internet and wireless communication, a recorded video can be utilized and viewed from anyplace on the planet. This is put to use to extraordinary impact in close to home living arrangements, as property holders are currently ready to use reasonable video reconnaissance as a type of home security.

Existing system consists of surveillance cameras for security and safety which requires a heavy setup. It needs someone to be $24 \times 7$ hrs in front of the screen to check out the activity (mischievous) when it's happening. It requires a lot of wiring and physical work to install the CCTV cameras. Since it requires heavy work it also costs very high for the system maintenance.

\section{The Proposed Application}

In this section we introduce our security camera notifier application. The main objective is the safety of the user's personal room with low cost when compared to surveillance cameras. Proposed system consists of a very small sized camera which is easy to install in a small personal room. User receives notification for any mischievous activity on Smartphone which decreases the work of $24 \times 7$ surveillance. Electricity consumption is very less when compared to surveillance cameras. An unknown person won't easily notice the camera been installed in the room. 
The system architecture applied for the proposed model is depicted in Fig 1.

There are 3 actors that play together to build up the application. The figure also depicts the communication between the actors.

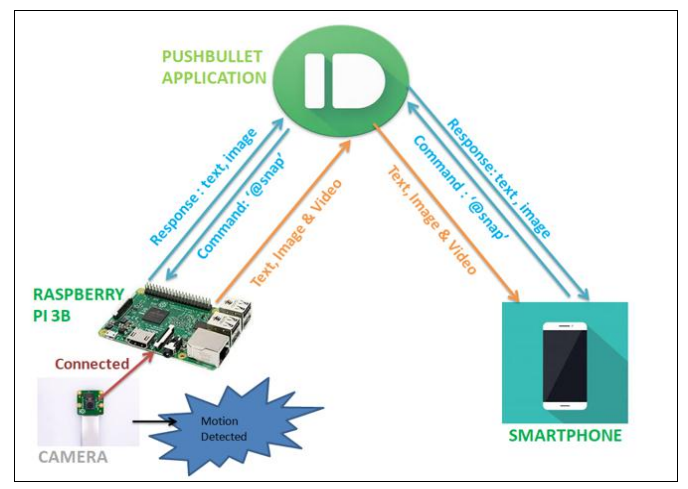

Fig.1. Security Camera Notifier System architecture

(1) Raspberry Pi and camera module as the information source that persistently checks for movement and recording video simultaneously.

(2) Pushbullet is the message-intermediary to send messages (content, despite everything picture, and recordings) to and fro between Raspberry Pi and Mobile/Web.

(3) Mobile/web goes about as "notifyee" who gets the still picture and video of movement. The communication is two different ways however. It implies you can send a command from mobile or web to Raspberry Pi for specific exercises, for example, "@snap" (for right away snap a picture).

The important hardware devices/tools used for the system are:

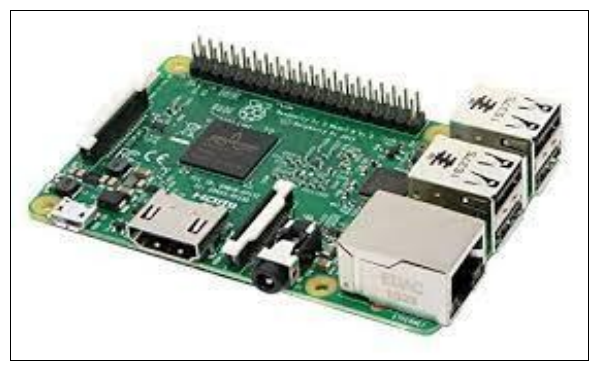

Fig.2. Raspberry Pi 3B Chip

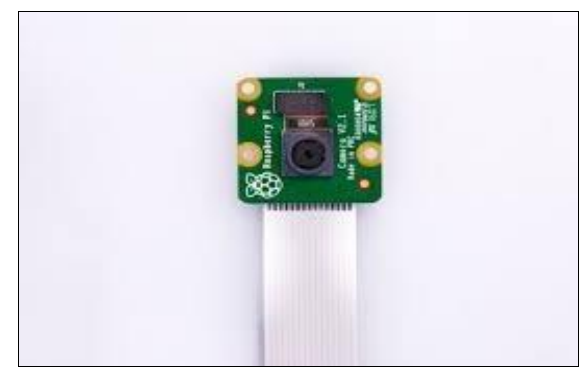

Fig.3. Raspberry Pi Camera Module V2 


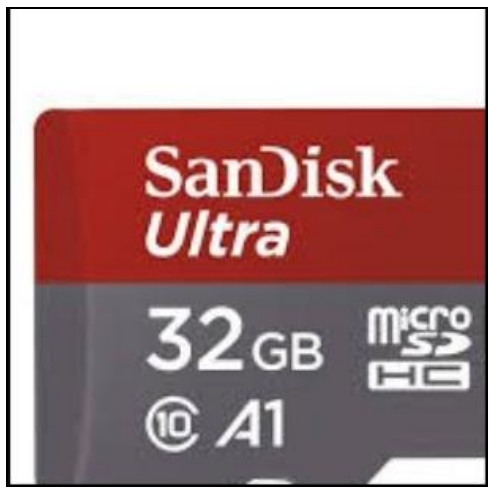

Fig.4. Memory card

To get started with Raspberry Pi, user needs an operating system. NOOBS (New Out Of Box Software) is a simple working framework to introduce supervisor for the Raspberry Pi.

Install NOOBS in an SD Card with Minimum of 16GB capacity. SD cards with NOOBS preinstalled are available from many of our distributors and independent retailers, such as Pimoroni, Adafruit and The Pi Hut. For older models of RaspberryPi, you'll need a full-size SD card; for the Pi Zero, A+, B+, Pi 2 and Pi 3 you'll need a micro SDcard Then connect all the Necessary device to Raspberry Pi including camera module.

\section{Download Noobs}

We recommend using an SD card with a minimum capacity of $8 \mathrm{~GB}$.

1. Using a computer with an SD card reader, visit the Downloads page.

2. Click on NOOBS, then click on the Download ZIP button under 'NOOBS (offline and network install)', and select a folder to save it to.

3. Extract the files from the zip.

\section{Format Your Sd Card}

It is best to format your SD card before copying the NOOBS files onto it. To do this:

1. Visit the SD Association's website and download SD Formatter 4.0 for either Windows or Mac.

2. Follow the instructions to install the software.

3. Insert your SD card into the computer or laptop's SD card reader and make a note of the drive letter allocated to it, e.g. F:/

4. In SD Formatter, select the drive letter for your SD card and format it.

\section{Drag And Drop Noobs Files}

1. Once your SD card has been formatted, drag and drop them onto the SD card drive.

2. The necessary files will then be transferred to your SD card.

3. When this process has finished, safely remove the SD card and insert it into your Raspberry Pi.

\section{First Boot}

1. Plug in your keyboard, mouse, and monitor cables

2. Now plug the USB power cable into your Pi. 
3. Your Raspberry Pi will boot, and a window will appear with a list of different operating systems that you can install. We recommend that you use Raspbian - tick the box next to Raspbian and click on Install.

4. Raspbian will then run through its installation process. Note that this can take a while.

5. When the install process has completed, the Raspberry Pi configuration menu (raspi-config) will load. Here you are able to set the time and date for your region, enable a Raspberry Pi camera board, or even create users. You can exit this menu by using Tab on your keyboard to move to Finish.

\section{Raspberry Pi Camera Module}

1. Open up your Raspberry Pi Camera module. Be aware that the camera can be damaged by static electricity. Before removing the camera from its grey anti-static bag, make sure you have discharged yourself by touching an earthed object.

2. Install the Raspberry Pi Camera module by inserting the cable into the Raspberry Pi. The cable slots and the connector are situated between the Ethernet and HDMI ports, with the silver connectors facing the HDMI port.

3. Boot up your Raspberry Pi.

4. From the prompt, run "sudoraspi-config". If the "camera" option is not listed, you will need to run a few commands to update your Raspberry Pi. Run "sudo apt-get update" and "sudo apt-get upgrade.

5. Run "sudoraspi-config" again - you should now see the "camera" option.

6. Navigate to the "camera" option, and enable it. Select "Finish" and reboot your Raspberry Pi.

When the script launches, it takes 2 seconds to heat up the camera to ensure everything works appropriately. At that point it hops directly into movement checking. When motion occurs, the Pi will capture picture and send warnings to the telephone right away. Simultaneously, Pi records the moment for a couple of seconds. For every threshold time Pi re-catches another picture and notifies the user. Until there is no more movement, the recorded recordings will be pushed to mobile to affirm the movement has finished. The framework goes into a movement examining state. The program loops again and again as in the flowchart.

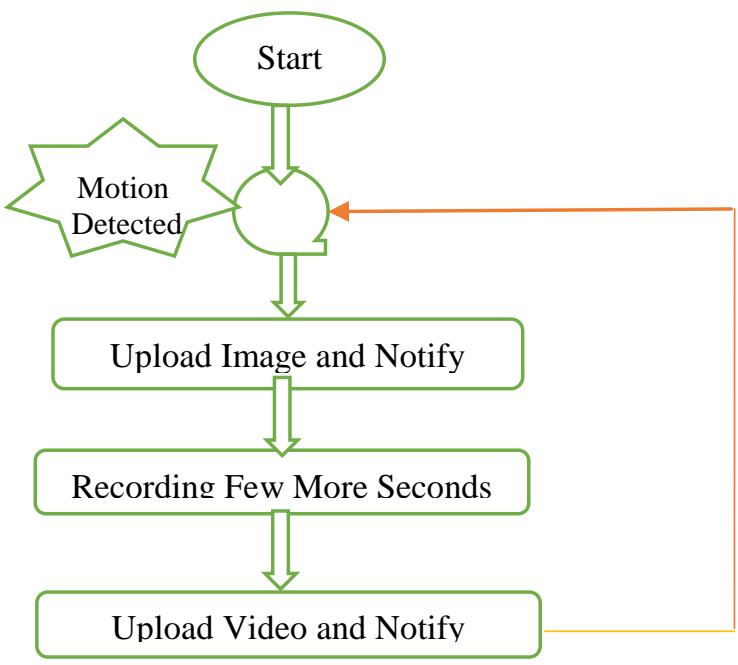

Fig.5. General Flowchart 
The proposed system consists series of events happening in a loop. The system starts when the device is connected to an internet source. The system scans for motion detection continuously. The moment it detects motion it sends a notification along with an image file to the user's pushbullet application and upload a video of motion detection after that. The user has an extra feature which can be used if he/she wants a live image at a specific moment they want by sending ‘@snap' message to the system via pushbullet application. These are the series of events happening in a flow.

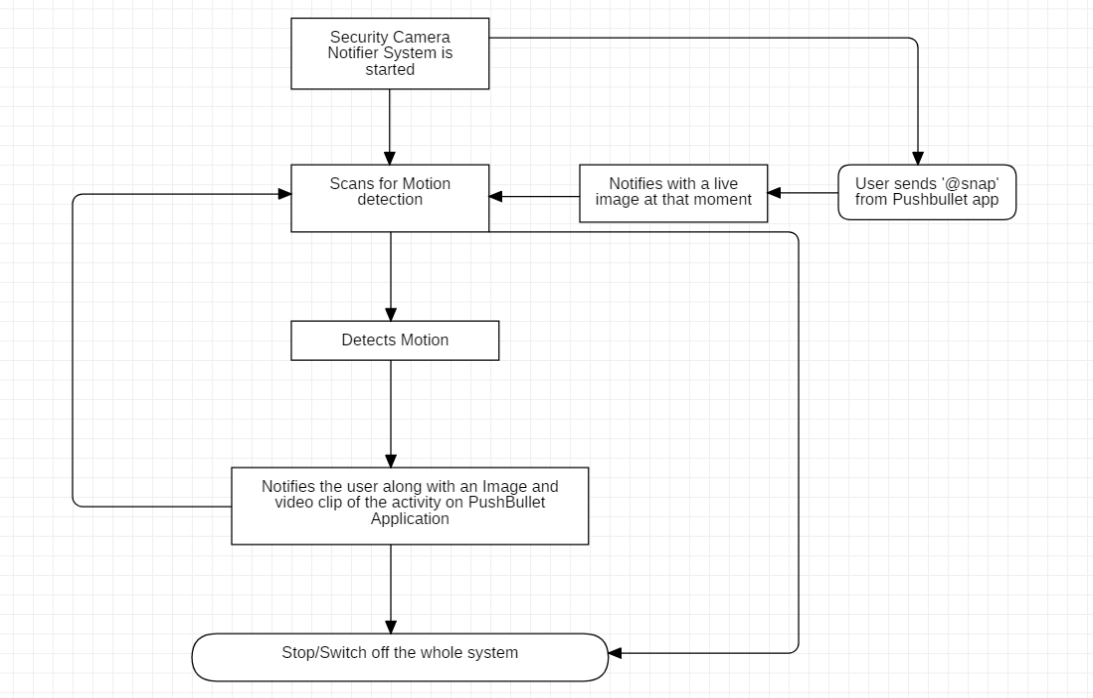

Fig.6. Event flow Diagram

\section{Results}

The expected things from the system is that when an unknow person enters the room our camera captures the image of the person and sends a notification to the user. The system should be always ON status so that it captures and notifies the user.

In this section, the results are discussed using screenshots of the events happening while the system detects any kind of motion. There are two important functionalities to be covered here. First one covers the motion detection events and the second one covers the further feature utilized by the user to have a live image of the moment using ‘@snap’.

\section{A. Motion Detection}

When the system is started on by connecting it to a power source, user gets a notification on pushbullet application stating 'PiCameraNotifier app starts!', this means that the system is connected to the internet and is ready to detect the motion.

Now, when the system detects any motion it sends a notification stating 'Hey! Someone sneak into your room. Check it out!' along with an image and video file of motion detection. 

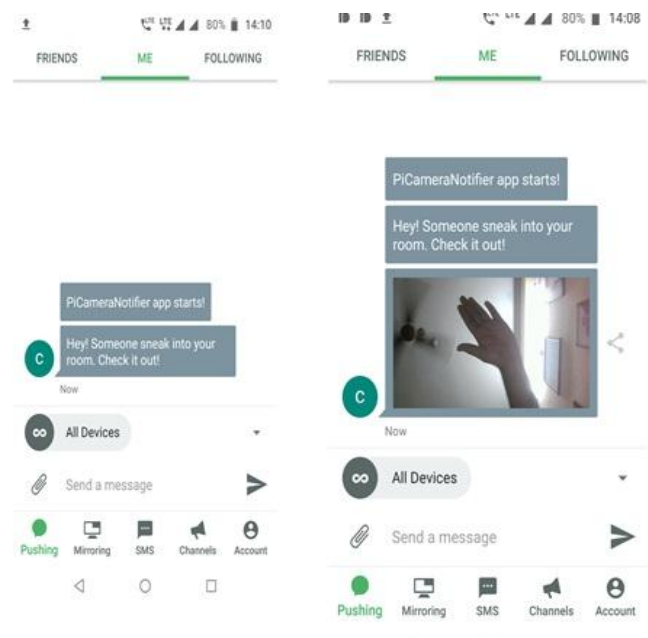

Fig.7. Motion Detection Notification (only Image)

The video of motion detection may take some time to upload and send as the size may defer based on the duration of the video.

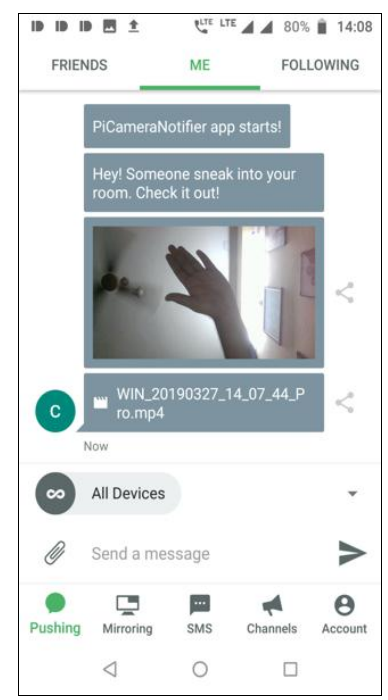

Fig.8. Motion Detection Notification (Along With Video)

\section{B. Motion Detection}

An extra component in the proposed system is ‘@snap' feature which can be used by the user to request for a live image of his/her room. The user simply just needs to type '@snap' in the pushbullet application while the system is on. The system will capture a live image and propel it to the user via pushbullet app. 


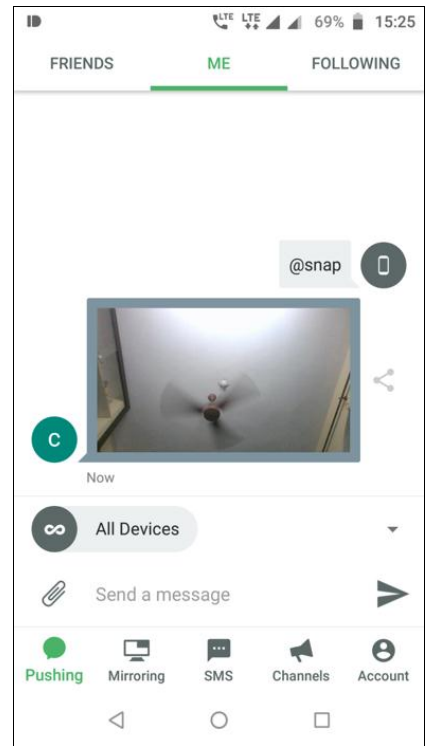

Fig.9. snap Function

\section{Analysis of the Results}

\section{Motion Detection of a Person}

This test case presents the screenshot of notifications when a person strolls before the camera depicted in fig . When the system is started user gets a notification stating 'PiCamera Notifier starts!'

Now, if the person walks before the camera for a longer duration user gets a progression of notifications with the images \& videos of motion detection on Smartphone. Following are the snaps of notifications for this case.

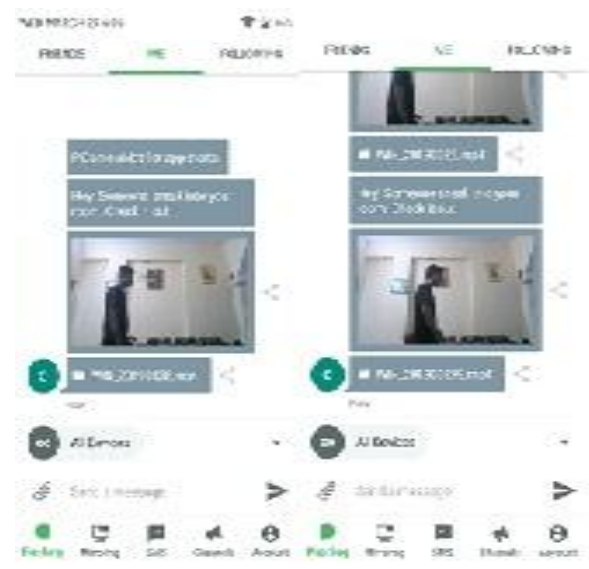

Fig.10. Test Case 1 


\section{Motion Detection of a Hand Movement}

This test case focus the screenshots of notifications send to user when a hand is moved before the camera as depicted in fig. Here also user gets a similar notification when the system is started, i.e, a notification stating 'PiCamera Notifier starts!'.

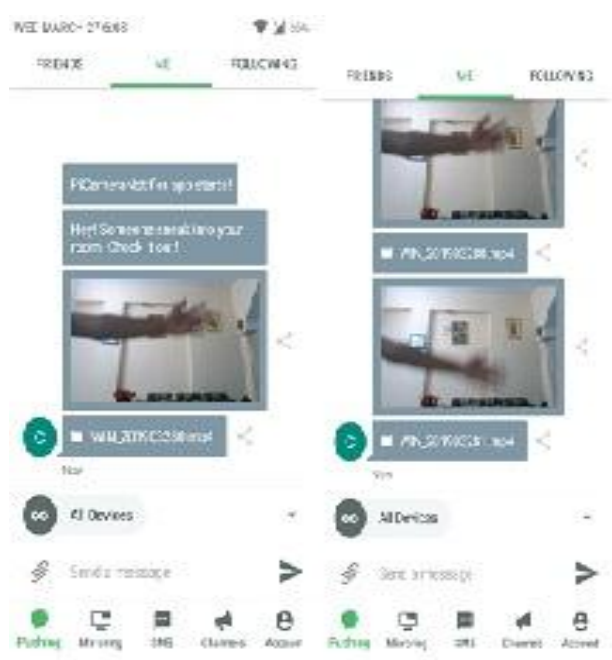

Fig.11. Test Case 2

\section{Motion Detection of an Object}

The third test case describes about the motion detection of an object, say fan in this case. When the fan is slightly moved, the camera considers it as motion detection and notifies user via Pushbullet app. Following are the snaps of system being initiated and series of notifications while the fan is even slightly moved.

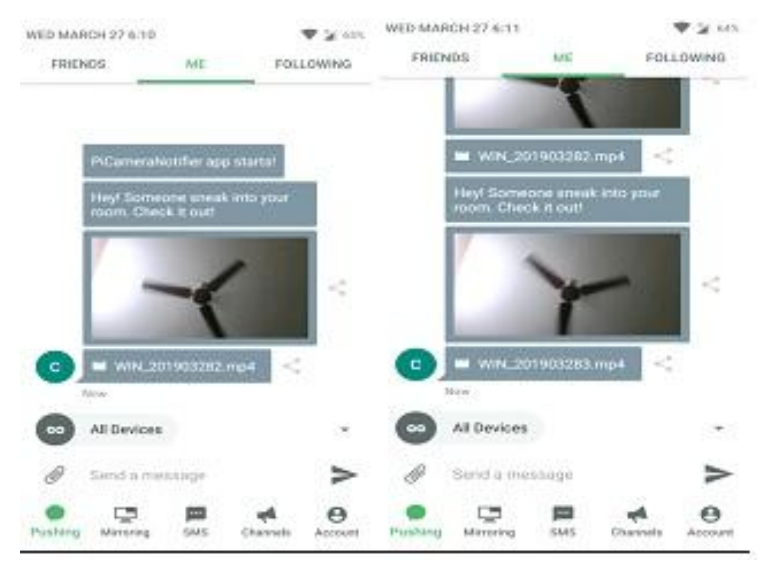

Fig.12. Test Case 3 


\section{Conclusions}

Through the proposed system, security is extended for personal rooms as it captures a snap or records the moment when the motion is detected in user's absence. It notifies to the Smartphone and also allows the user to have a live image of the room at any moment and hence establishing a two-way communication system.

The proposed system can be enhanced by implementing image processing applications such as face recognition so that user gets notified only when a specific person enters the room. The system can also be enhanced by using night vision cameras so that the motion can be detected even in the darkest regions. The proposed system can be collaborated with an alarm setup such that it starts ringing when an unknown person enters the room in user's absence.

\section{References}

[1] IEEE History Center: Development of VHS, cites the original name as "Video Home System", from an article by Yuma Shiraishi, one of its inventors. Retrieved December 28, 2006.

[2] "VHS, Beloved Home Video Format, Dies at 40". ScreenCrush. Retrieved 2016-09-09.

[3] Newhall, Beaumont (1982). The History of Photography. New York, New York: The Museum of Modern Art. p. 13. ISBN 0-87070-381-1. Joseph Nicéphore Niépce, of exposure to light.

[4] Leslie Stroebel and Richard D. Zakia (1993). The Focal encyclopedia of photography (3rd ed.). Focal Press. p. 6. ISBN 978-0-240-51417-8.

[5] "VCR and Home Video History". Television History - The First 75 Years. TVhistory.TV. Retrieved 24 May 2011.

[6] "Ampex VRX-1000 - The first commercial videotape recorder in 1956". Cedmagic.com. 1956-04-14. Retrieved 2010-05-31.

[7] VHS, Beloved Home Video Format, Dies at 40". ScreenCrush. Retrieved 2016-09-09

[8] The Betamax vs VHS Format War, Author: Dave Owen, Originally published: 2005". Mediacollege.com. Retrieved 2012-09-16

[9] The History of Magnetic Recording". BBC 20 December 2004. Retrieved 15 March 2011.

[10] Intelligent video surveillance system, 26-29 Oct. 2017, Virgil Claudiu Banu ; Ilona Mădălina Costea ; Florin Codrut Nemtanu ; Iulian Bădescu, Electronic ISBN: 978-1-5386-1626-0

[11] Sushant Kumar ; S. S. Solanki : Remote home surveillance system, 29 September 2016, Electronic ISBN: 978-1-5090-0673-1.

[12] Zhengya Xu ; Hong Ren Wu: Smart video surveillance system, 27 May 2010, Electronic ISBN: 978-14244-5697-0

[13] K. N. Karthick Kumar ; H. Natraj ; T. Prem Jacob: Motion activated security camera using raspberry Pi, 08 February 2018, Electronic ISBN: 978-1-5090-3800-8

\section{Authors' Profiles}

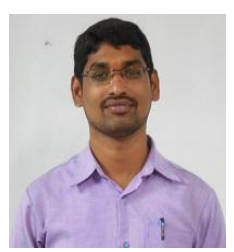

K Murali Krishna, born in 1986 and working as Assistant Professor in Maturi Venkata Subba Rao Engineering College, Telangana. His area of Interest includes, IoT, Security, Software Defined Networks, Computer Networks and Blockchain. 


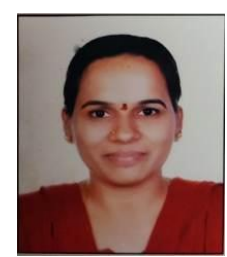

Dr H Jayashree working as Professor in Maturi Venkata Subba Rao Engineering College, Telangana. Her Area of Interests includes Network Security, Congestion in Networks, Cyber Security.

How to cite this paper: K Murali Krishna, H Jayashree, " A Novel IoT Based Approach to Notify Motion Detection in User's Absence through Handheld Devices ", International Journal of Wireless and Microwave Technologies(IJWMT), Vol.10, No.3, pp. 45-55, 2020.DOI: 10.5815/ijwmt.2020.03.04 